\title{
Evaluation of Existing Pedestrian Facilities and Its Potential Improvements
}

Piyush Pashupati Pandey, Anirudh Mathur, Nikhil Kumar Sharma

Department of Civil Engineering, Swami Keshvanand Institute of Technology, Management \& Gramothan, Jaipur302017 (INDIA)

Email: piyushpandey2210@gmail.com, anirudh.mathur@skit.ac.in, nikhil.sharmacivil@skit.ac.in

Received 1.07.2021, received in revised form 6.08.2021, accepted 7.08.2021 doi: $\underline{10.47904 / I J S K I T .11 .2 .2021 .16-21 ~}$

\begin{abstract}
Walkability is a mostly used way of moving from one place to other. In recent times it has been affected due to the rise in vehicles on the road and it reduces the smooth mobility of pedestrians. Jaipur has seen a rapid increase in population and no. of accidents. Stretch is selected based on land use as it is $3.6 \mathrm{~km}$. problems were identified and public opinion was also carried out to find out their concerns and needs. Based on their responses, suggestions and improvements are provided.
\end{abstract}

Keywords- Pedestrian Facilities, Safety, Accidents, Walkability, Google Earth Pro, Measurements.

\section{INTRODUCTION}

Walkability has been the foremost used means of movement from the early settlement of our civilization. It has helped in minimizing the gap between different ethnicities and developing relations among mankind. The augmentation in motorized transport has eroded the space for pedestrian movement and affected the walkability habits of the road user. The capabilities of pedestrians and their characteristics also face huge setbacks from consequent mobility eruption. Even the process of planning our cities has changed keeping driving as the main mode of transportation rather than giving pedestrians their deserved right of way.

As of 31st March 2017, the total number of registered Transport vehicles was 22.539 million which includes 8.9 percent Transport Vehicles and $91.1 \%$ Non-Transport Vehicles. Transport Vehicles include LMV (Goods) and LMV (Passengers) with 30.6\% and $25.1 \%$ respectively. The share of Trucks, Taxis \& Buses is $19.3 \%, 12 \%$, and $5.9 \%$ respectively. Nontransport Vehicles include Two Wheelers and Cars with $81 \%$ and $12.43 \%$ [1].

Nowadays our societies are more concerned about social status and how they are being treated in terms of wealth and power by others. Cars have become the status symbol which has resulted in a reduction of walking habits as well as in less usage of available public transportation. The quantitative factors showcase the change in walking behavior in terms of reduced trip lengths. In the context of pedestrian footpaths, about 30 percent of the roads in most Indian cities are provided and pedestrians contribute to almost 20 percent of road accidents in India [2].

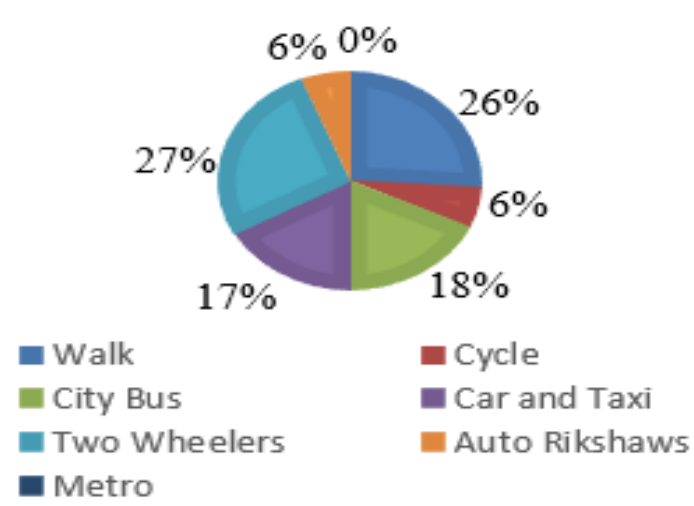

Fig. 1 Modal Share in Jaipur City Transportation (in percent)

Analysis of modal share also indicates that the current pattern promotes energy inefficiency, causes traffic congestion, pollutes the environment, and pushes up the economic, personal, and social costs of commuting [3].

As per provisional reports of Census India, the population of Rajasthan in 2011 is 6.89 crores and the population of Jaipur in 2011 is 30,73,350. Jaipur ranks 1 st in terms of population, 9th in terms of area, and 1st in terms of population density. Jaipur district covers an area of 11143 sq. $\mathrm{km}$ with a gross developed area density of 595 persons per sq. km. Decadal population growth of 26.45 percent was observed in Jaipur district which is more than Rajasthan having a growth of 21.31 percent [4].

In recent times Jaipur has faced this issue of lack of space on roads even after widening. This is mainly due to congestion created by the large no. of vehicles being purchased and it has resulted in conflicts that occurred between pedestrians and vehicles. The conflict does happen between vehicles and nonmotorized transport also

\section{LITERATURE REVIEW}

Walking encompasses many activities made on foot be it playing, running, jogging, standing even socializing too. With numerous concerns, such as health issues, excessive use of non-renewable resources, air, and noise pollution, walking can help us in defeating these issues and creating a sustainable solution.

Mixed uses allure different populations at different times for different reasons that make for a lively 
public domain resulting in greater personal security because of natural surveillance. Single dominant land use produces customers with the same schedules viz some in mid-afternoon or office workers at lunchtime, making the spaces less populated at other hours [5].

New Zealand Pedestrian Planning and Design Guide recognizes 9 primary characteristics of a true walkable society- connected, legible, comfortable, convenient, pleasant, safe, secure, universal, and accessible [6].

For a better pedestrian crossing, locating a proper site with a specific consideration can ensure pedestrian convenience and safety. If not provided, pedestrians may cross at random locations, causing traffic disorder and hazardous to both pedestrians and vehicular flow. In the case of walking the death rate is $25 \%$ of the death rate of overall traffic accidents [7].

The most vulnerable users of the transportation system are pedestrians. Short paths are preferred safe by the pedestrians and the remaining half of the road is crossed significantly with higher speed. Pedestrian-crossing problems arise with the construction of flyovers. One of the factors causing women not using stairs was fear of the darkness due to less lightning and illumination as they feel more secure in light. Old-age people will get help by lightning as they have less visibility [8].

$92 \%$ pedestrian sample gives the negative feedback on the safety questions based on all the pedestrian opinions and analysis, various recommendations and pedestrian facilities are proposed on the selected intersections. Due to less knowledge about the zebra crossings (62\% only), there is also the requirement of public awareness program [9].

On-foot access is nearly declined steadily in most cities, where high-speed traffic breaks up pedestrian networks forcing barriers that affect the flow movement of walkers. Taking no notice of walkability can result in mislay intimate scale and clarity of routes and less of a healthy human lifestyle [10].

\section{OBJECTIVES OF THE STUDY}

The study is based on the assumption that the physical characteristics of stretch and neighborhood can influence walking behaviors.

The objectives of the study are:

i. To identify and investigate the present status of existing pedestrian scenarios in terms of available pedestrian facilities.

ii. To find out the need of pedestrians as per their suitability and requirements. Also, their concerns with the current situation.

iii. To provide suggestions for enhancing walkability on the selected stretch.

\section{NEED OF THE STUDY}

There is a large no. of coaching centers, shopping stores, and offices on the stretch from Gopalpura Flyover Junction to Gurjar ki Thadi Underpass. Due to the high frequency of motorized transport on the road, it has been difficult for the road user especially pedestrians to walk and to move around facing hostile situations due to the traffic.

The foundation for the widening of the road was laid down by the then Government of Rajasthan in 2015 and notices were sent to many shops and buildings. The cost of the project was estimated to be around 95 crores. After the process of widening was done by demolishing existing buildings, there is an occurrence of fast movement of vehicles due to which pedestrian feels unsafe.

The stretch selected was of Gopalpura Flyover Junction to Gurjar ki Thadi Underpass and the length of the selected stretch is $3.6 \mathrm{~km}$.

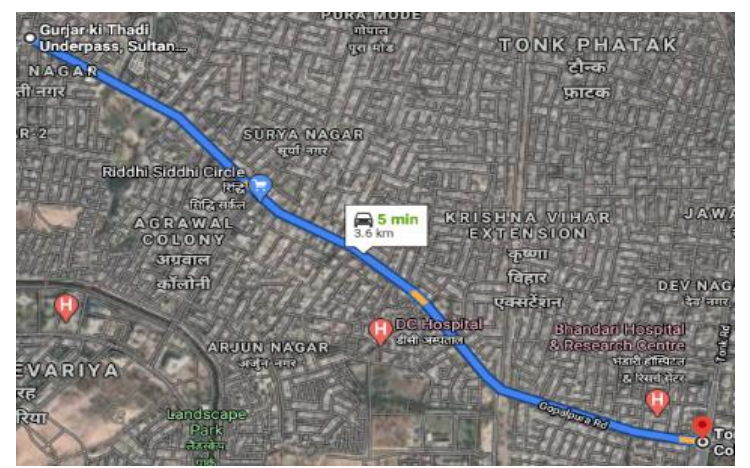

Fig. 2 Length of the stretch between Gopalpura Flyover Junction to Gurjar ki Thadi Underpass.

\section{SCOPE OF THE STUDY}

The study takes up the identification of walkability scenarios on the stretch only. The choice excludes all such stretches that fall outside the limits. The walkability scenario is examined based on various variables and benchmarks developed from the literature review.

\section{METHODOLOGY}

The process of methodology comprises of following steps as following:

\subsection{Road Inspection}

The visual inspection was done when the restrictions were eased down just before the announcement of the next lockdown. Pictures and Videos were taken to understand the current condition and also to identify spots requiring more attention.

It also helped to understand the flow of traffic movement and human behavior in certain situations. The lack of bus stops, pedestrian facilities such as footpaths, crosswalks, pedestrian refuge, channelizing islands, roadside amenities show the 
sheer need for attention towards improving the existing pedestrian situation.

By observing the above picture, it can be seen clearly that how the absence of midblock crossing will create problems to movement of pedestrians from one side to the other.
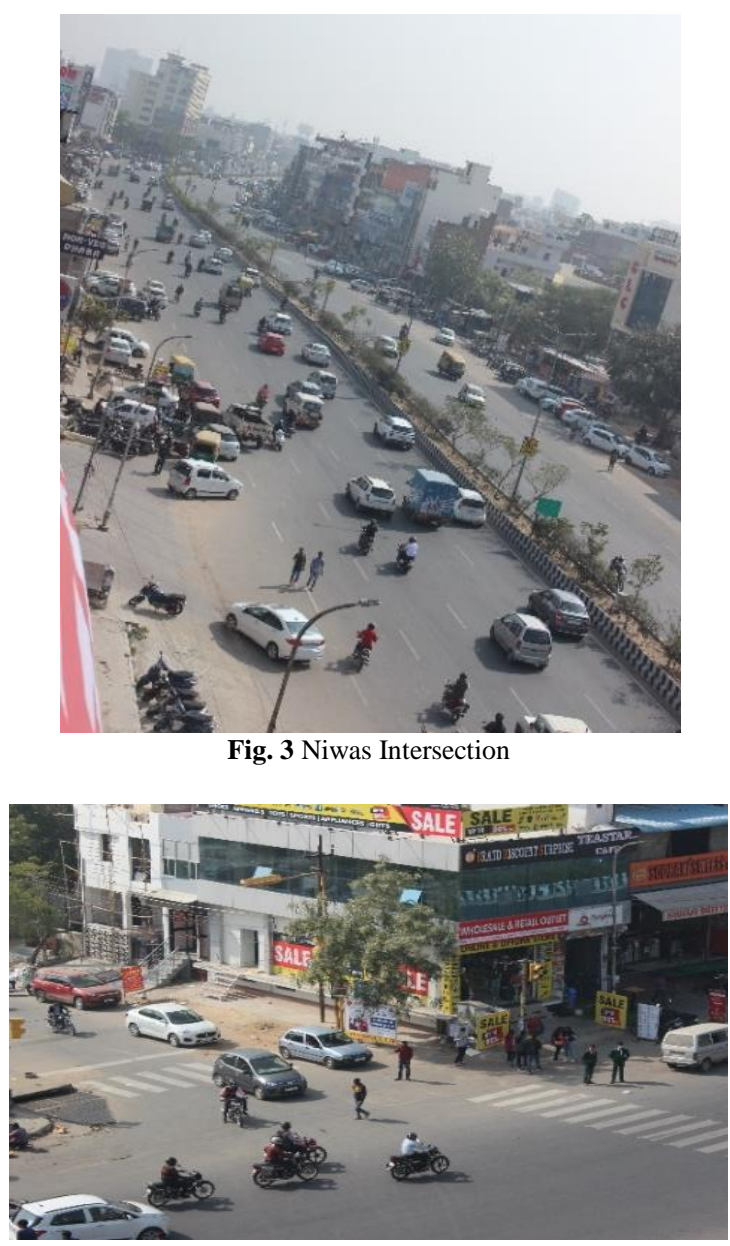

Fig. 4 Narayan Niwas Intersection

In the above picture, it can be observed that how pedestrian refuge on crosswalks can help in achieving the safety concerns of pedestrians.

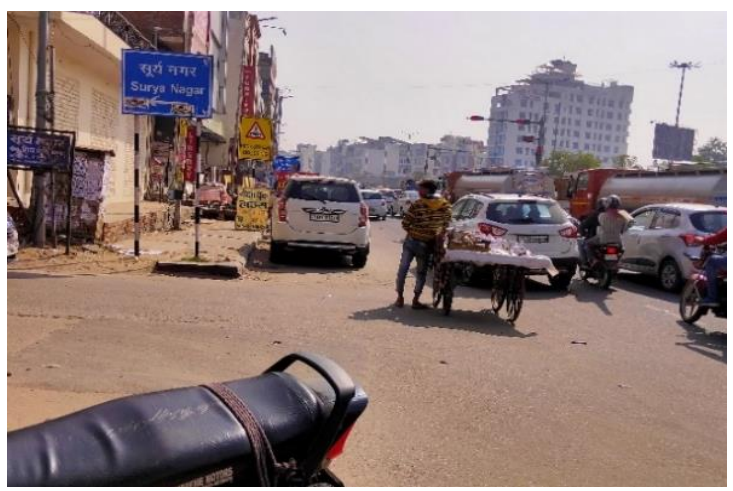

Fig. 5 Riddhi Siddhi Circle

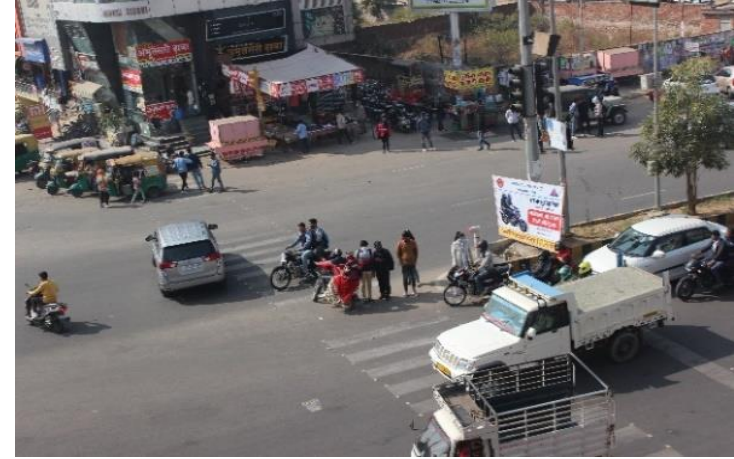

Fig. 6 Riddhi Siddhi Circle

This is also one of the examples where pedestrian refuge is missing and the encroachment on the carriageway is also needs to be monitored regularly.

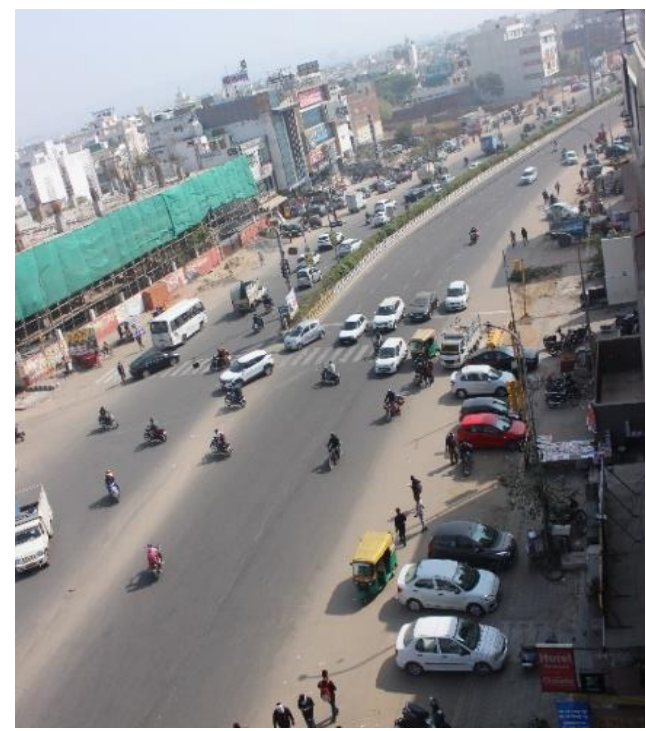

Fig. 7 Abhigyan Coaching Institute

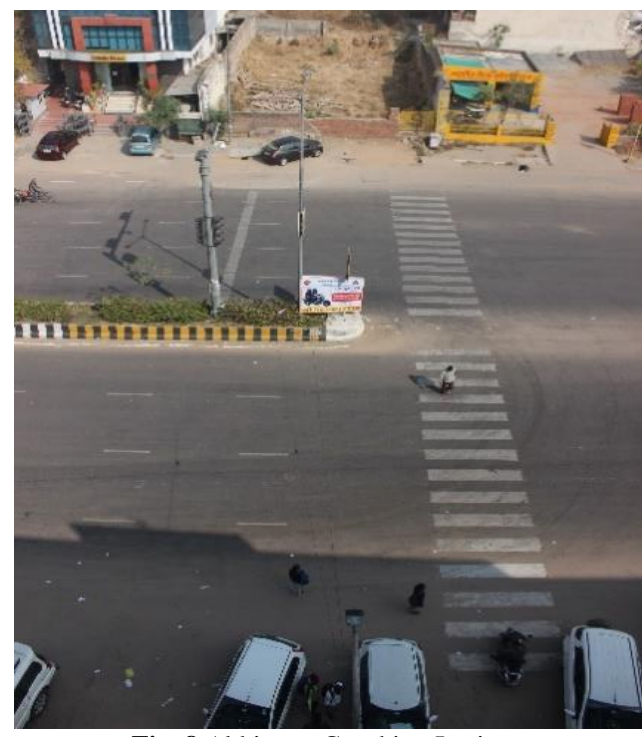

Fig. 8 Abhigyan Coaching Institute

The picture was taken from the roof of the Abhigyan Coaching Institute. It can be seen that irregular 
parking happens due to improper designing and allocation of space.

\subsection{Data Collection}

It includes data of the number of accidents in Jaipur in different years from the city office of traffic department i.e., Yadgar office. Due to COVID-19 restrictions, it could not be done hence the online sources were found to be useful for the required data.

Table 1 Accidents Reported in Jaipur (Source: (Road Accidents Data, 2017)

\begin{tabular}{|c|c|c|c|c|}
\hline Years & $\begin{array}{c}\text { Two- } \\
\text { Wheel }\end{array}$ & Bus/Truck & Car/Jeep & Others \\
\hline 2010 & 5405 & 6875 & 6741 & 5281 \\
\hline 2011 & 4891 & 6604 & 6588 & 5162 \\
\hline 2012 & 4968 & 6428 & 6484 & 5089 \\
\hline 2013 & 5249 & 6431 & 6587 & 5325 \\
\hline 2014 & 5955 & 6331 & 6888 & 5454 \\
\hline 2015 & 5865 & 5903 & 7329 & 4975 \\
\hline 2016 & 5736 & 5295 & 7389 & 4646 \\
\hline
\end{tabular}

The numbers of accidents for pedestrians and cyclists are given in the other section of the table. The proper segregation of data could not be obtained.

The data collection of road geometry and other dimensions of various elements present on road were measured by using Google Earth Pro as restrictions did not allow to do the measurements physically.

The use of Google Earth Pro helped in doing the work more efficiently and also it helped in observing the present condition of the road in aerial view.

The following process can be used to obtain the dimensions of the required element:

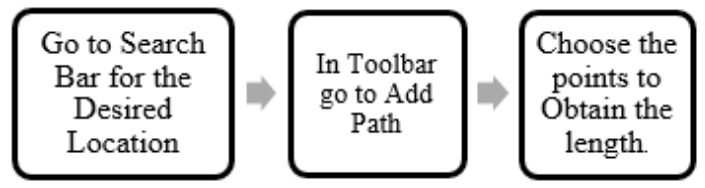

Fig. 9 Measurements in Google Earth Pro

The image shown below represents the process when implemented in Google Earth Pro. The main advantage of using it is that we can choose the orientation of the site and take the measurements as per the requirements by even changing the time frame to suit our needs and to make comparison with time.

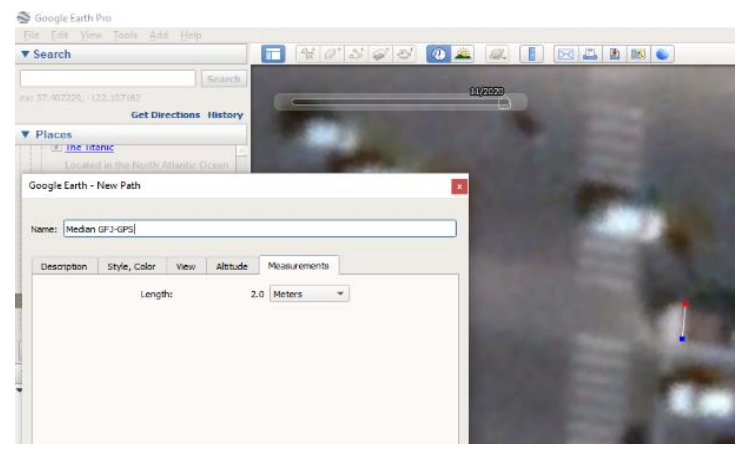

Fig. 10 Median Width Measurement in Meters

\subsection{Public Opinion about Existing Condition}

To examine the public opinion and their needs the Google form was created which comprises of two sections.

The first section consists of questions about personal details such as Email, Age, and Gender.

The second section consists of questions about their opinion about the existing condition of the selected stretch. To find out the needs of pedestrian and local population a survey was conducted using Google Forms. It was circulated through WhatsApp and other ways to get the responses.

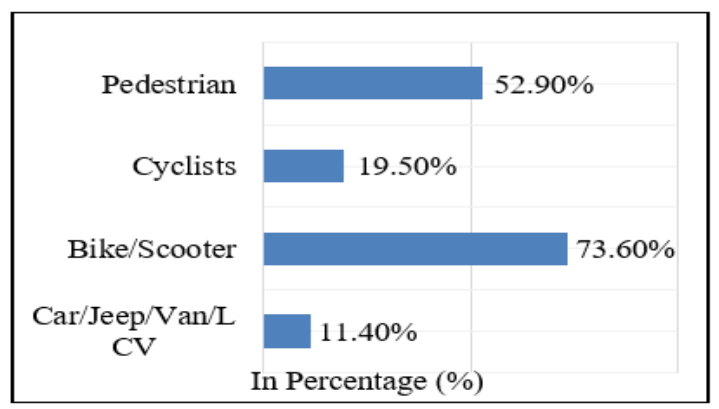

Fig. 11 Question-2.1 Your Vehicle Class

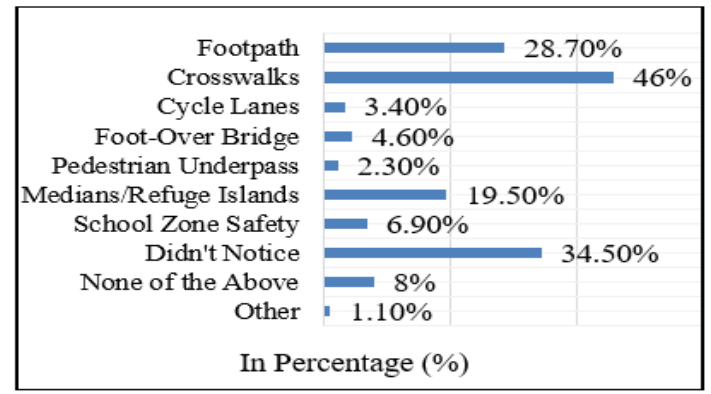

Fig. 12 Question-2.3 Which Facility you found for Pedestrian and Cyclist?

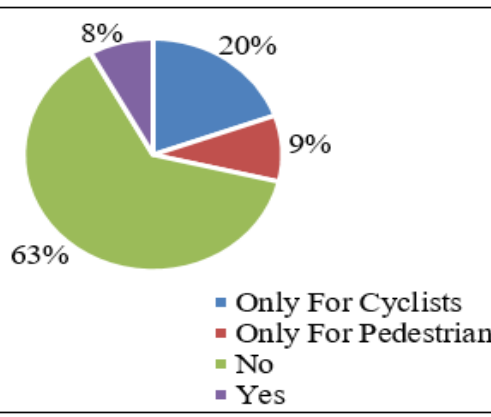

Fig. 13 Question 2.8 - As a Road User do you Feel Safe for Pedestrians and Cyclists

\begin{tabular}{|c|c|}
\hline Benches/Furniture & $9.20 \%$ \\
\hline Street Trees & $8 \%$ \\
\hline Street Lighting & $62.10 \%$ \\
\hline Luggage Lockers & $=5.70 \%$ \\
\hline Public Toilets & $8 \%$ \\
\hline Parking Provision & $18.40 \%$ \\
\hline Didn't Notice & $35.60 \%$ \\
\hline None & $=3.40 \%$ \\
\hline & In Percentage $(\%)$ \\
\hline
\end{tabular}


Fig. 14 Question 2.9 What are the Amenities observed on the Stretch?

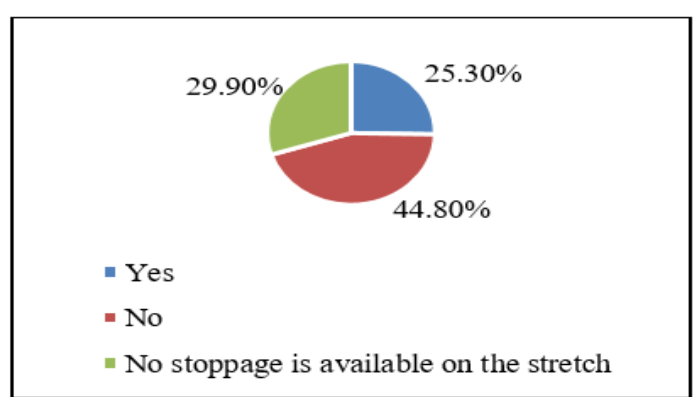

Fig. 15 Question 2.11-Do Buses, Autorickshaws, and other mode of Public Transport stops at their desired location?

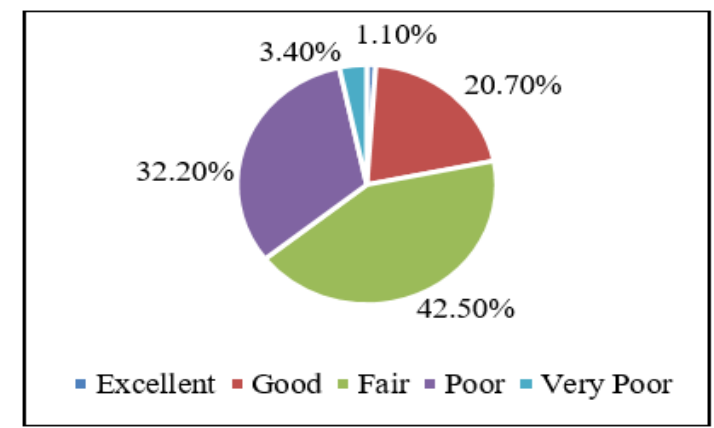

Fig. 16 Question-2.12 Rate Existing Condition on your Overall Experience

Based on collected data and visual inspection, it can be seen that widening of road hasn't helped much in reducing the problems of congestion.

\section{RESULTS AND DISCUSSION}

As per the observations on the selected stretch, it was found to be unsafe for pedestrians and cyclists to achieve safer movement. This can be supported by the responses that resulted in more than $60 \%$ feeling unsafe. The provisions of pedestrian and cyclists' facilities are much needed to ensure the sense of safety in the minds of road users.

There is a need for improvements in the existing road markings as during the time of inspection it was observed that few of the markings were not proper in terms of visibility.

Pedestrians are considered to be the most vulnerable road users but we must not forget that specially-abled person feels most insecure crossing and moving on the streets. More than $50 \%$ of respondents did not find any facility or provision for the specially-abled person. Proper slopes, signals dedicated to them, etc. can result in important changes.

To ensure systematic movement of vehicles it is necessary to provide bus stops and other stoppage points which can enhance the connectivity with other elements on the roads. The responses assist the argument with only 1 in 4 respondents finding bus stops at their desired locations.

\section{CONCLUSION}

Road inspection survey shows that the current condition of incorrect and unclear road marking, foot-path conditions, bus stops, etc. So, there is a requirement for these improvements for a safer pedestrian environment and proper road markings at the intersection.

The importance of making our streets public-friendly and open to all users is required by providing amenities as discussed by Tibbalds et al. (2005) for safer and lively by providing natural surveillance. This will generate more revenue and encourage others to increase their visits to different hours also. Not only safety but connectivity also plays a major role in deciding whether the provided facilities are either a success or a failure. A study in New Zealand also suggests that accessibility and connectivity with safety create a pleasant environment for road users. Every class of road users and every individual must be considered while planning for pedestrian infrastructure. Dass et al. (2015) emphasize short paths and proper lightings which can help old-age people to maneuver easily.

To ensure safer crossings, the provision of a footover bridge and pedestrian underpass can fulfill the requirements. The locations will be the main concern due to the large no. of incoming roads connecting the main road from the streets.

Construction of Slip lanes, public awareness, and strict law enforcement can fill the gap of rest issues.

\section{FUTURE SCOPE OF THE WORK}

The future scope can consist of modeling and designing the suggestions using drafting software such as AutoCAD, Civil 3D. It will help in visualizing the developments made after the suggestions and also it can be formulated that how things will work out.

\section{REFERENCES}

[1] Road Transport Yearbook (2016-17). Ministry of Road Transport and Highways. New Delhi.

[2] Study on Traffic and Transportation Policies and Strategies in Urban Areas in India (2008). Ministry of Urban Development. New Delhi.

[3] Mehta, S. (2019). Assessment of Urban Mobility in Jaipur: Jaipur Development Authority.

[4] India, C. o. (2011). DISTRICT CENSUS HANDBOOK, Jaipur: Directorate of Census Operations.

[5] Tibbalds, F. (2005). Making People-Friendly Towns: Improving the Public Environment in Towns and Cities. London and New York: Spon Press.

[6] Agency, N. T. (2008). Pedestrian Planning and Design Guide. Auckland.

[7] Zhang, D. Q. (2010). Improvement of Pedestrian Crossing Safety on Urban Roads. International Conference on Intelligent and Computation Technology and Automation IEEE Computer Society.

[8] Sachin Dass, (2015) Study of Pedestrian Flow/Behavior on Indian Roads. IOSR Journal of Mechanical and Civil Engineering, 38-42. 
[9] Rahul M. Kasundra, P. P. (2016). Planning of Basic Pedestrian Facilities at Selected along at The intersection of Rajkot City. Surat: Global Research and Development Journal for Engineering.

[10] Sulaiman, I. (2020). Walkability in different Contexts in neighborhood planning: an overview. Architect. Res. 10 (1), $27 \mathrm{e} 43$. 